\title{
Effects of phytohormones on mycelial growth and exopolysaccharide biosynthesis of medicinal mushroom Phellinus linteus
}

\author{
Xia Guo · Xiang Zou · Min Sun
}

Published online: 23 June 2009

(C) Springer-Verlag 2009

\section{Erratum to: Bioprocess Biosyst Eng}

DOI 10.1007/s00449-009-0326-9

In the article, doi: 10.1007/s00449-009-0326-9, "Phellinus linteus" had been misspelled as Pellinus linteus in the Title and Keywords. "Naphthaleneacetic acid" had been misspelled as "Naphthalentacetic acid" in Abstract, Keywords, and Introduction section. The fault lies solely on the authors.

The online version of the original article can be found under doi:10.1007/s00449-009-0326-9.

\section{Guo $\cdot$ M. Sun $(\bowtie)$}

Key Laboratory of Eco-environments in Three Gorges Reservoir Region, Ministry of Education, School of Life Sciences, Southwest University, 2 Tian Sheng Road, Beibei, 400715 Chongqing, People's Republic of China e-mail: jwcsm@swu.edu.cn

X. Guo $\cdot$ X. Zou $(\bowtie)$

College of Pharmaceutical Sciences, Southwest University,

2 Tian Sheng Road, Beibei, 400715 Chongqing,

People's Republic of China

e-mail: zhx1030@yahoo.cn

\section{Zou}

Chongqing Municipal Key Laboratory on Luminescence and Real-Time Analysis, CQKL-LRTA, College of Chemistry and Chemical Engineering, Southwest University,

400715 Chongqing, People's Republic of China 